\title{
The Environmental Science/Policy Interface: Crossing Disciplinary Boundaries with a Team-Teaching Approach
}

\author{
David Schlosberg, Northern Arizona University \\ Thomas D. Sisk, Northern Arizona University
}

\section{Introduction: The Problem}

It is no secret that few policymakers are well versed in the sciences, and it should come as no surprise that many scientists are unfamiliar with the process of formulating and implementing public policy. In fact, many students choose to study politics in order to focus on "real world" issues and to avoid the rigors of laboratory sciences. Likewise, other students often choose a science major to avoid the seemingly irrational operations of policy development and the political arena. As a result, there is an inherent tendency for students of science and policy to operate in separate educational and, later, professional worlds.

This cleavage between science and politics, while admittedly oversiplified, has become part of the intellectual baggage passed implicitly to students in many fields in the natural and social sciences. Teaching courses in environmental politics

David Schlosberg teaches political theory and environmental politics as an assistant professor of political science at Northern Arizona University. His recent publications include Environmental Justice and the New Pluralism 1Oxford, 1999), and Debating the Earth: The Environmental Politics Reader, edited with John Dryzek (Oxford, 1998). He was named NAU's "Teaching Scholar" of 1999.

Thomas D. Sisk teaches ecology, conservation biology, and environmental policy in the Center for Environmental Sciences and Education at Northern Arizona University. From 1994 to 1996 he served as assistant to the director of the National Biological Service, U.S. Department of the Interior. In addition to publications on basic and applied ecology, he recently edited Perspectives on the Land Use History of North America: A Context for Understanding Our Changing Environment (U.S. Geological Survey, 1998). and policy, for example, one very quickly encounters a problem. Much environmental politics and policy emerge from the claims and findings of the natural sciences, information that is articulated in a very distinct language from that in which public policies are debated and codified. Whether dealing with policies on the emission of greenhouse gases, the liquidation of old-growth forests, or environmental health, teaching environmental politics demands attention to science. Unfortunately, few undergraduates in political science have a thorough understanding of the scientific process, much less the intricacies of global climate change, ecosystem function, toxicology, or other areas of environmental research.

Similarly, students of biology, chemistry, geology, and other natural sciences often receive excellent training in environmental sciences without receiving even a rudimentary exposure to how science is or (more likely) is not incorporated into the development of environmental policy. They may leave the university with a thorough understanding of scientific processes while remaining clueless about the policy process. Science students are trained to generate and interpret knowledge, but few carry with them a framework for ushering that knowledge into the policy arena, where it is urgently needed to help solve some of the most pressing problems facing humanity.

Simply put, there is a lack of scientific training for those studying environmental policy, and a lack of political and policy training for those studying the environmental sciences. The separation of disciplines produces students incapable of fully understanding environmental issues and unable to effectively mobilize their specialized knowledge to improve and effectively implement policy in an integrated manner. Few students leave the university with the capability of following an issue from the realm of scientific inquiry into the realm of politics.

\section{Bridging the Gap: Interdisciplinary Approaches}

This quandary has not gone unrecognized, and there are numerous ways political science and environmental sciences programs have attempted to address the issue. Many require their students to take courses offered by other departments. Many courses in applied science contain modules on the policy process, and many environmental policy courses draw on science. This exposure to other disciplines and ways of knowing adds valuable perspective to both undergraduate and postgraduate education; however, a module or course here or there is seldom sufficient to prepare scientists for effective participation in the policy process, and is almost never sufficient to provide political scientists with the understanding needed to interpret most scientific results.

At Northern Arizona University, political science majors interested in environmental politics can take an extended major in American political studies with an emphasis in environment. Students in this program supplement their training in environmental politics with courses from other disciplines, including the humanities and the sciences. All students in the environmental sciences program are required to take one core course in environmental policy. And the environmental sciences em- 
phasis in environmental policy and administration, one of eight choices for an area of concentration, ensures that students receive a strong foundation in biology, geology, and chemistry, along with public administration, the policy process, environmental policy, environmental movements, and green political theory. Still, students can get through the American political studies major without taking a single science course, and the vast majority of environmental science majors, in emphases other than politics, take only the one introductory course in environmental policy. Many other universities offer similar programmatic options, with similar disciplinary limitations.

\section{Needed: Integration, Not Merely Exposure}

We celebrate the move toward interdisciplinary curricula, but we have discovered in our short time teaching in such programs that they do not fully address the problem. We may have advanced in terms of giving students the opportunity to be exposed to the different disciplines. But nowhere are students required to integrate the methods and lessons from both politics and natural sciences. Soulé and Press (1998) recently discussed the dangers of shallow interdisciplinary approaches in teaching environmental studies, arguing that expanding educational breadth has led to a shallower treatment of all subjects. But certainly, even rigorous presentation of essential core topics will fail to create interdisciplinary scholars if the interfaces between disciplines are not explored explicitly.

In our experience, both within the university and in the policy arena, accomplished students may leave the university with an understanding of both scientific and political processes, but they seldom have the opportunity to examine exactly how the two relate: How do political or social issues affect the construction of environmental science? How do the findings of environmental science inform the development of environmental policy? And how does

\section{Shaping the Preparation of Future Social Science and Humanities Faculty}

Working as part of a program sponsored by the Council of Graduate Schools (CGS) and the Association of American Colleges and Universities (AAC\&U), APSA will award grants to support the "Preparing Future Faculty" programs of four Ph.D. departments working with political science departments in (a combination of) nondoctoral universities, colleges, and community colleges.

The CGS and AAC\&U have received a private gift of $\$ 1,635,000$ to support Shaping the Preparation of Future Social Science and Humanities Faculty, which addresses the preparation of future faculty in the social sciences and the humanities. CGS and AAC\&U will coordinate the work of six social science and humanities disciplinary associations involved with the initiative. The initiative builds on and extends the Preparing Future Faculty (PFF) program that CGS and AAC\&U have led since 1993 with support from The Pew Charitable Trusts and the National Scierice Foundation. The new program brings research universities, the "producers" of Ph.Ds., and colleges and universities, the "consumers" who hire Ph.Ds., into partnership. The partners will offer faculty preparation that highlights the broad mission of undergraduate education and the diverse needs and characteristics of students entering the academy. Doctoral degree-granting departments will form partnerships with similar academic departments in institutions ranging from community colleges to comprehensive universities to create learning laboratories to train graduate students in the broad range of faculty responsibilities. The six associations engaged in the initiative are the American Historical Association, American Political Science Association, American Psychological Association, American Sociological Association, National Communication Association, and National Council of Teachers of English.

Each participating society will select at least four doctoral degreegranting departments to receive grants of $\$ 10,000$ a year for two years. Over a two-year period, the departments will create innovative faculty preparation programs based on Preparing Future Faculty concepts. Throughout the implementation of the new programs, the societies and higher education organizations will disseminate their findings to their constituencies and promote new thinking about the professional development of future faculty.

Applications will be reviewed by APSA's PFF Advisory Committee composed of Kristi Andersen, Syracuse University, chair; Constance E. Cook, director, Center for Research on Learning and Teaching, University of Michigan; Charles A. Johnson, Texas A\&M University and chair, APSA Committee on Education and Professional Development; and Ronald M. Peters Jr., University of Oklahoma and chair, APSA Committee on Departmental Services.

For more information, visit the APSA web site (www.apsanet.org). Inquiries should be directed to Sheilah Mann at smann@apsanet.org. 
the process of making environmental policy incorporate or distort possible lessons from the natural sciences?

Probing the issues raised by an examination of the elusive interface between science and policy was the task we set for ourselves when we-a political theorist and an ecologistproposed a team-taught course titled "Science, Politics, and Environmental Policy."1 Our central focus was an examination of how scientific knowledge is generated, presented, understood, and applied as various political forces shape the development of environmental policy.

\section{Charting a Course that Explores the Science/Policy Interface}

Through discussions with policy professionals, research scientists, and students, we identified three fundamental objectives for a semester-long course focusing on the science/policy interface.

1. Consider perspectives from ecology, political science, economics, and sociology, and explore how they can be used to critically examine environmental science and environmental policy development and implementation.

2. Examine criticisms of both science and policy processes articulated by academics, governmental agencies, interest groups, and grassroots organizations.

3. Explore how scientific claims are commonly misrepresented and misused in policy formulation, particularly to support various ideological ends.

The class was offered for either political science or environmental science credit and, not surprisingly, a wide variety of students enrolled, including undergraduate and graduate students in political and environmental sciences (as well as a few curious faculty and staff). In our team-teaching approach, we presented integrated lectures to a diverse class; both of us fully participated in each day's presentation. ${ }^{2}$
We hoped our own perspectives and biases, as well as those of the students, would come quickly to the fore, be recognized and discussed, then fused in both daily dialogue and, later, as we worked through several in-depth case studies. ${ }^{3}$

We began the class with introductions to both the scientific process and the policy process, discussing in both instances the model rational process and the corruptions that often distort it. We wanted to call students' attention to the similarities between the rational model of policy making and the traditional model of scientific inquiry. In both, one begins with a question or problem, employs a logical, often linear, thought process to identify possible explanations, then rigorously evaluates these with empirical data before selecting the most parsimonious solution. But employing this rational process is problematic in both the political and scientific realms. In policy design, there are a number of limitations to, and corruptions of, the process. We examined the real-world obstacles to rational policy making, such as the imprisoning effect of the market, as well as incrementalism, or "muddling through" (Lindblom 1959, 1982).

We also examined some of the limitations of experimental approaches in the natural sciences. Reducing complex issues to component problems amenable to experimentation often results in "answers" that are so narrowly focused or sitespecific that they are irrelevant in the policy arena. Similarly, more realistic and complex approaches typically incorporate a greater number of parameters, each of which is estimated with some uncertainty. This cumulative experimental error often leads researchers to make predictions with a large degree of associated uncertainty, leaving scientific approaches vulnerable to criticism from those unaccustomed to operating within a probabilistic framework.

We took this issue one step further in an examination of fisheries management models. Most students assumed that more realistic and complex models would be more appropriate than simpler, less realistic models for setting harvest levels.
Our examination of ecological models (admittedly highly simplified) served to demonstrate how complex approaches, with a large number of parameters, often generate predictions with high levels of uncertainty that ultimately prove less useful in policy contexts than simpler, less realistic models whose parameters can be estimated accurately (see Ludwig and Walters 1989). The issue of coping with uncertainty in scientific approaches became a lively theme throughout the remainder of the semester.

In both disciplines, the "rational" model has real limitations. Science students were quite interested in the difference between rational and incremental models of policy making; politics students were surprised to discover the trade-offs (and subjectivity) involved in developing scientific studies.

A major portion of the course was spent examining the misuse of environmental science for political ends. We focused specifically on critiques of the politicization of science (Ehrlich and Ehrlich 1996), and examined various social institutions and forces that directly and indirectly influence the policy process, including science education, the media, and the public relations industry. Students weren't surprised to hear of the chemical industry's attempts to discredit Silent Spring, but were taken aback by the numerous continuing examples of attacks, orchestrated by public relations firms, on the scientific claims of authors writing on pesticides, meat production, and toxic sludge (see, e.g., Stauber and Rampton 1995), as well as the sheer amount of environmental education materials for grades $\mathrm{K}-\mathrm{I} 2$ produced by the nation's largest polluting industries. Importantly, we examined a number of places and issues where the scientific and policy processes cross paths: risk assessment, cost-benefit analysis, and the processes of public participation and public hearings in the development of environmental policy. Students noted the subjectivity involved in setting the parameters of risk in, for example, pesticide exposure for children. Conversely, they were impressed by the scientific acumen of- 
ten displayed by lay people during public hearings. ${ }^{4}$ Finally, we examined some alternative relationships between science and policy. Specifically, we discussed the shift in focus that adoption of the precautionary principle would pose (Montague 1998) and suggestions for more public participation in guiding science (e.g., Sclove 1995) and in guiding the application of environmental science (e.g., Fischer 1995).

In laying out the course, we wanted to focus not only on the specific issue of the relationship between science and policy, but also on the broader question of how we know and see the "environment" and how those varied knowledges may be brought into the political process. Both politics and science students were shocked and challenged by the paradigm-questioning critiques raised in postmodern and feminist writings on science (Haraway 1988; Keller 1985; Ross 1996), but it was crucial to directly address the way knowledge-both political and scientific-is objectively situated. Acknowledging that science has a social context helped students recognize the legitimacy of different ways of seeing issues through either scientific design or everyday experience. We then discussed recent designs for a democratic and discursive policy process (Dryzek 1990; Healy 1993; Young 1996), which would be more open to acknowledging and including these varied ways of seeing the environment and environmental problems.

\section{The Value of In-Depth Case Studies}

In an attempt to ground the theories, we focused the final third of the course on in-depth case studies of specific issues. For one local issue- the complex problems underlying management of the Colorado River from Glen Canyon Dam through Grand Canyon National Park ${ }^{5}$-we invited experts at the center of the science/policy vortex into the classroom. During successive sessions, we had the past and present research directors of the
Bureau of Reclamation's Grand Canyon research program address the class on specific research and management issues, as well as their personal experiences working at the interface of science and policy. The speakers addressed the same issue, and drew from the same history and databases, but their views, approaches, and assessments of the success of science in supporting policy were widely divergent. One talked about the degraded river ecosystem, efforts to remove the dam, and the potential of restoration, referring to the extensive research conducted over the past decade and the value of that data in political battles with dam proponents. The other discussed the role of science in providing the information needed to guide dam operations as managers attempt to meet the divergent demands of utility companies, water managers, and recreationalists while protecting the natural resource. Each speaker grounded himself in a particular scientific reading of the issue and conveyed very different concepts of how scientific inquiry might contribute to improved river management. It was clear that the students' initial responses were to align behind one perspective or another, bolstering their gut reactions with the best supporting arguments that the available information would allow. As the problem analysis was carried back into readings and discussion, the class began to appreciate, in a very palpable way on an important local issue, the complexity of doing science and applying the findings in the policy arena.

We then explored both the scientific basis and the policy development process for a number of other current environmental issues. These included the Endangered Species
Act, with the case of the northern spotted owl providing a textbook example of the interplay between ecological science and management policy; the health effects of dioxin, focusing on the changing perception of scientific studies and the "spin" of interpretation within the policy arena; and global climate

change, where we studied how efforts to quantify scientific uncertainty have been misused to undermine policy initiatives backed by a considerable body of scientific evidence and a general consensus among leading researchers. These studies allowed students to thoroughly examine both the science and politics of current issues. They also were used to demonstrate to students a set of relevant applications of the various literatures we had surveyed.

During the last weeks of the course, students presented their own group projects. Teams including both natural science and social science majors examined the scientific and policy processes of issues of their own choosing. The assignment was for teams to follow an issue in both the realms of science and policy, and to reflect on the various influences to which the scientific and policy processes were subject. This exercise was designed, in part, to bring these differently-trained students together to produce a study critical of both disciplinary realms. Students examined nuclear waste disposal, organic food policy at the U.S. Department of Agriculture, reintroduction of the Mexican wolf, grazing policies, and habitat conservation in the face of urban sprawl. They were required to make a presentation to the class in addition to submitting a single team-written research paper.' 


\section{Conclusion}

The reviews of the course ${ }^{7}$ were overwhelmingly positive (with the exception of a few gripes about the heavy reading load). Interestingly, both the science students and the social science students said the course gave them a greater perspective on their own discipline, in addition to letting them learn about what had been "foreign territory." The word "relevant" appeared on nearly every evaluation, and students seemed genuinely thankful for the opportunity to breech the disciplinary boundaries and integrate the numerous points of knowledge nec- essary in order to more thoroughly understand environmental issues.

It is, after all, true that policymakers increasingly are being required to consider cutting-edge science when formulating environmental policies, and environmental scientists are also being asked to step into the policy arena. If our students in the political and environmental sciences are any indicator, a majority have been inspired to pursue these courses of study precisely because they want to work effectively on environmental problem solving. They recognize and accept the interdisciplinary nature of these issues. We see no reason to believe that the discontinuity that has characterized the science/policy interface in the past need be passed on to the next generation of environmental scientists and policymakers. Our experiences suggest that with guidance and exposure to the relevant literature, students specializing in either field will be able to survive-even thrive-at the science/policy interface, and that they will work effectively together, drawing on their differing expertise, skills, and experiences to address complex problems that lie between traditional disciplines.

\section{Notes}

1. We should note that we may have been at a bit of an advantage over those at other institutions in proposing this course. NAU has a focus on environmental issues as part of its mission, and administrators and faculty have been increasingly dedicated to developing interdisciplinary approaches to the topic. Both political science and environmental sciences have been at the forefront of such efforts. Still, this was the first course teamtaught and cross-listed across the two programs, and we wish to acknowledge the support of our chairs and deans.

2. We saw this as true "team teaching" rather than the oft-used model of "tag-team teaching," where instructors alternate lectures (often with the other instructor absent).
3. The syllabus and research assignment are available for viewing at http://jan.ucc. nau.edu/ dss4/499Syllabus.htm

4. Lectures and standard readings were supplemented with guest lectures, videos, governmental reports, and the publications of various environmental organizations.

5. Glen Canyon Dam generates electricity, stores and controls distribution of limited water resources to several western states, and provides recreational opportunities for thousands. Its operators determine the amount and timing of water released downstream, profoundly influencing the Grand Canyon ecosystem, including the populations of several endangered species.

6. One could go on about the benefits and liabilities of a team project, though that would take another article. We recognized the different abilities and energies of students on teams, as well as the problem of freeriding. To deal with these potential difficulties, we had students rate their teammates' contributions on a scale of 1-10; we then gave the team members not a single grade, but a range (e.g., 86-94). Individual students were given a grade within that range which reflected both the teams' and the instructors' evaluations of their particular work.

7. Courses at NAU have both numeric and written evaluations. Our course was rated a 4.5 on a scale of 5-significantly above the average score in either political science or environmental sciences.

\section{References}

Dryzek, John. 1990. Discursive Democracy: Politics, Policy, and Political Science. Cambridge: Cambridge University Press.

Ehrlich, Paul R., and Anne H. Ehrlich. 1996. Betrayal of Science and Reason. Washington, DC: Island Press.

Fischer, Frank. 1995. "Hazardous Waste Policy, Community Movements and the Politics of Nimby: Participatory Risk Assessment in the USA and Canada." In Greening Environmental Policy: The Politics of a Sustainable Future, ed. Frank Fischer and Michael Black. New York: St. Martin's Press.

Haraway, Donna. 1988. "Situated Knowledges: The Science Question in Feminism as a Site of Discourse on the Privilege of Partial Perspective." Feminist Studies 14(3): 575-99.

Healy, Patsy. 1993. "Planning through De- bate: The Communicative Turn in Planning Theory." In The Argumentative Turn in Policy Analysis and Planning, ed. Frank Fischer and John Forester. Durham, NC: Duke University Press.

Keller, Evelyn Fox. 1985. Reflections on Gender and Science. New Haven: Yale University Press.

Lindblom, Charles. 1959. "The Science of Muddling Through." Public Administration Review 19(Spring): 79-88.

—. 1982. "The Market as Prison." Joumal of Politics 44(2): 324-36.

Ludwig, D., and C.J. Walters. 1989. "A Robust Method for Parameter Estimation from Catch and Effort Data." Canadian Joumal of Fisheries and Aquatic Sciences 46(1): 137-44.

Montague, Peter. 1998. "The Precautionary
Principle." Rachel's Environment \& Health Weekly, February 19.

Ross, Andrew. 1996. "Introduction." In Science Wars, ed. Andrew Ross. Durham: Duke University Press

Sclove, Richard. 1995. Democracy and Technology. New York: Guilford Press.

Soulé, Michael E., and Daniel Press. 1998. "What Is Environmental Studies?" BioScience 48(5): 397-405.

Stauber, John, and Sheldon Rampton.1995. Toxic Sludge Is Good For You! Lies, Damn Lies, and the Public Relations Industry. Monroe, ME: Common Courage Press.

Young, Iris Marion. 1996. "Communication and the Other: Beyond Deliberative Democracy." In Democracy and Difference: Contesting the Boundaries of the Political, ed. Seyla Benhabib. Princetrin: Princeton University Press. 